\title{
On the Connotation and Construction of Red Integration into the Ideological and Political Education Under the Perspective of CAS Theory
}

\author{
Han $\mathrm{Lu}^{1, \mathrm{a}}$, He Ruting ${ }^{2, b^{*}}$ \\ ${ }^{1}$ Business School Nanfang College of Cong Hua, Guang Zhou, Guang Dong, China \\ ${ }^{2}$ Academy of Politics Business Studies Nanfang College of Cong Hua, Guang Zhou, Guang Dong, China \\ a84540305@qq.com \\ b*3289109420@qq.com
}

\begin{abstract}
The red gene is the gene code that has been flowing in the blood of the Communist Party of China, an important achievement of the sinicization of Marxism, and a high embodiment of the political ideals and practical needs of Communists. It is characterized by a revolutionary and advanced nature. Colleges and universities are at the forefront of education, and shoulder the general requirements of cultivating people by virtue.Based on CAS theory with red gene as the core, in the form of flow through the whole process of university growth, to college students comprehensive development as the coordinate, the needs of college students, with multiple education main body, multiple education field nonlinear fusion as the basis, in the road of cultivating college students to form a benign development of red culture education ecosystem.From the same perspective of education, education and interactive education examine the red gene as the construction logic of the ideological and political education ecosystem. From the CAS theory, the ideological and political education ecosystem has two basic ecosystems, namely "Self-education ecosystem" and "humanistic education ecosystem", On the basis of these two basic ecosystems, the educational norms of "mutual education ecosystem" have emerged.Based on the education system in the new era and the perspective of self-education, education and mutual education, starting from the three aspects of concept convergence, field joint construction and system homogenization, so as to better explore the value of red gene in universities and promote universities to complete the fundamental task of education.
\end{abstract}

Keywords: Red gene; CAS theory; university; ecosystem

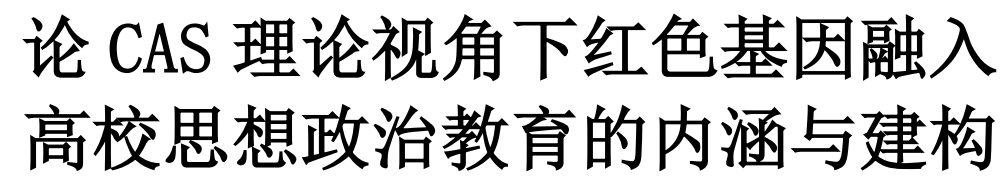

韩 露 1 , a 何茹婷 ${ }^{2} \mathrm{~b}^{*}$

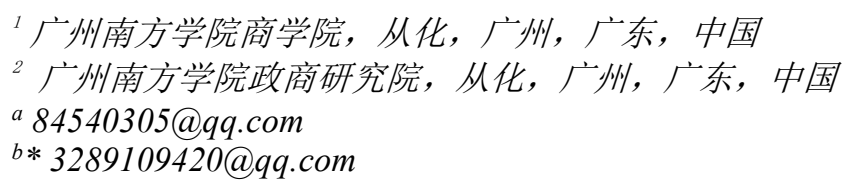

摘要

红色基因是一直流淌在中国共产党血液中的基因密码，是马克思主义中国化的重要成果，是共产党人政治理 想、现实需求的高度体现，具有革命性、先进性等特征。高校是育人的前沿阵地，担当着立德树人的总要求。 基于 CAS 理论以红色基因为核心，以流的形式贯穿于大学成长的全过程，以大学生全面发展为坐标，以大学生 的需求为基点, 以多个育人主体相互聚集, 多个育人场域非线性融合为基础, 在培养大学生成长成才的道路中 
形成一个良性发展的红色文化育人生态圈。从育己、育人和互育同等视角审视红色基因融入高校思想政治教育 生态圈的建构逻辑，从 CAS 理论出发分析高校思想政治教育生态圈共有两个基本生态圈即 “育已生态圈”、

“育人生态圈” ，以及基于两个基本生态圈下涌现出来的 “互育生态圈” 的育人规范。立足于新时代的育人体 系以及育己、育人和互育角度出发, 从理念同向、场域共建以及系统同构三大层面入手，从而更好地挖掘红色 基因在高校的价值, 推动高校完成育人的根本任务。

关键词: 红色基因; $C A S$ 理论; 高校; 生态圈

\section{CAS 理论下红色基因融入思政教育形成“生 态圈” 的内涵探绩}

红色基因是中国共产党将马克思主义中国化的 基础上, 带领全国人民在长期的革命、建设、改革的 实践中总结凝练出来的 “文化基因” ，一直流淌在中 国共产党血液中, 是百年来中国共产党不断开拓进取, 艰苦卓绝奋斗的文化解释密码, 高度体现了中国共产 党的初心使命、政治理想、现实需求、优良作风等, 具有革命性、先进性等特征。习近平总书记指出: “要 教育引导全党大力发扬红色传统、传承红色基因。” [1] 学生在大学生涯是青年思想走向成熟的重要阶段, 需要高校担负起相应的培养责任, 落实立德树人的根 本任务, 传承红色基因。当前高校已经形成诸多措施 来继承和弘扬红色基因, 但这些措施并不能够深入地 去挖掘红色基因的价值。CAS 理论的 3 种机制(标记、 内部模型和积木）与 4 个特性（聚集、非线性、流和 多样性), 这些洞见为研究学科的复杂性如何涌现和 适应设定了一个新路标。红色基因融入高校的思想政 治教育涉及多主体、多场域、多层次, 用 CAS 理论进 行分析和挖掘其深层价值, 与高校的思想政治教育有 机结合, 构建生态圈模式, 有助于让在高校更好地培 育大学生。

\subsection{CAS 理论的基本概述}

CAS 理论的 3 种机制（标记、内部模型和积木） 与 4 个特性（聚集、非线性、流和多样性）的具体含 义:（1）、聚集：在一定条件下, 主体在双方的接受 和相互作用下而相互聚集, 在这个过程中主体会取得 新的发展, 主体间相互适应, 并涌现出复杂行为, 形 成一个新的聚集体。这是 CAS 理论中最基本的特性。

(2)、非线性: 在 CAS 中所有的主体和场域都不是 按照简单的数学线性相加相乘规律, 而是非线性的, 打破传统的线性规律, 并随之产生更大的复杂性。(3)、 流: 在 CAS 中, 各主体和场域中会有能量的流动, 这 种流动伴随着时间的流逝和在各场域各主体之间的 经验积累而产生适应性, 具有乘数效应和再循环效应。 (4)、多样性: 在 CAS 中, 多样性通常具有持存性和 协调性, 主体会在发展的过程中保持自己独特的性质,
并在演化的过程中不断发展和提升自己。(5)、标记: 在 CAS 中标记是普遍存在的机制。标记在主体相互作 用时能够提供相互选择，区分主体之间的差异。(6)、 内部模型: 在 CAS 中每个主体内部都存在着复杂机制, 有显性和隐性之分, 能对行为结果进行有效的预知。

（7）、积木: 复杂系统是由积木所搭建而成, 每一层 积木的搭建都能为下一层积木提供基础, 促进新系统 的涌现。

\subsection{CAS 理论与生态圈的契合}

教育生态学是认识和掌握红色基因融入思政教 育构建生态圈的内涵意蕴关键和重要依据。古人在教 育生态学上, 已经有很长远的研究历史以及古人的独 特见解。从 “性相近, 习相远也” 到 “孟母三迁” 等, 这些无疑都表现出周围各种环境因素对育人主体心 理、生理等因素的影响。这无疑具备生态学上的一些 观点, 但由于思想观念等条件的限制, 古人无法研究 出更加科学的教育生态圈, 让育人主体得到全面性的 发展。而与过往的理论观点不同, 马克思从现实的人 出发, 提出 “人们是自己的观念、思想等等的生产者” ${ }^{[2]}$ ，并且 “生产本身又是以个人彼此之间的交往为前 提的” ${ }^{[3]}$ 。马克思用 “现实的人” 在教育中取得现实 的精神需要, 并在现实中与其他主体之间产生精神的 碰撞、聚集而获得自己的精神上发展, 强调在与他人 的交互和现实的实践过程。马克思的教育观念给新时 代高校思想教育指向了明确方向, 更适用于当前教育 的三全育人体系的实施过程, 要厚植于深厚的社会精 神土壤和主体支撑, 根植于育人主体的现实需要, 着 眼于教育的多样性发展, 在教育过程中处理好主体之 间的关系，构建教育的生态圈，实现知识谱系的传导。 而当下, 社会精神土壤无疑就是基于灿烂的红色基因 形成的精神体系。

在近代, 教育生态学得到了进一步的发展, 源于 对人的行为活动的生态研究。代表性较强的是克雷明 提出的观点, 他认为: “教育是通过周密的、系统的 和持久的努力来传播或激发知识、态度、价值、技术 和情感的过程。” ${ }^{[4]}$ 他将教育类比于一个生态系统, 这个系统是复杂、有机、统一的系统, 知识在这其中 充当着能量在主体之间不断传递着, 主体在传递的过 
程中不断获得知识、价值、技术，甚至是价值观、世 界观以及人生观的改善和提升, 这也是知识在传递中 的结果。需要用整体、联系的眼光看待问题, 每一种 教育上出现的情况都会对其他主体教育行为产生影 响, 是密切不可分开的。无论是包括学校、教育机构 还是教师、学生家长、行政人员等育人主体在内, 都 应该关注其行为举止, 这都会对育人对象产生影响。 而另外一个具有代表性的是阿什比的高等教育生态 学研究。阿什比针对大学的遗传性质提出: “为了生 存, 一所机构要满足两个条件: 必须足够稳定地保持 它得以产生的理念, 必须有足够的行动同支撑它的社 会保持联系。” ${ }^{\left[{ }^{5}\right]}$ 他认为所有生物都以适应生存为基 础, 而作为培育人的机构, 也需要适应生存, 而大学 要适应生存, 就必须要与社会保持联系, 与社会其他 主体相互作用, 共同培育大学生, 为社会服务。大学 生是高校的主体, 大学需要适应社会发展, 大学生则 需要适应大学的环境, 这种环境特性就要求大学生必 须具备足够的行为去不断适应这个大学环境, 需要具 备一定的适应性。

综合分析, 基于教育生态学构建的教育生态圈具 有复杂性、适应性、多样性等特征, 在教育生态系统 的能量传导中, 知识的精神体系是无时无刻存在着, 以及主体之间的相互影响是时刻进行着。呈现出来的 基本特性与 CAS 理论不谋而合。CAS 的核心观点认为 “适应性造就复杂性。” ${ }^{[6]}$ 即主体在适应周围复杂环 境时, 与其周围其他主体进行碰撞、相互作用, 在这 个持续开展的过程中不断吸收、学习或进行经验的累 积, 并依据所学改变做出相应的改变。主体在主动性 指引下, 促使它与内外环境进行反复交互作用, 从而 涌现新层次, 促进系统的演变。红色基因融入大学生 日常思政教育体系构建思政教育的生态圈, 基本特征 上符合 CAS 理论所缔造的系统模式, 与 CAS 理论的七 个概念高度契合。利用 CAS 理论视角分析, 旨在有效 提升对红色基因融入高校大学生日常思政工作的认 识, 为系统内思政教育生态圈的形成、构建提供理论 指导。

\section{3. 构建 “生态圈” 的基本条件}

基于以上 CAS 理论以及生态圈的特征, 结合红色 基因融入高校思想政治教育的本质属性, 我们可以将 高校红色基因融入思想政治教育构建生态圈的定义 为: 以红色基因为核心, 以流的形式贯穿于大学生成 长的全过程, 以大学生全面发展为坐标, 以大学生的 需求为基点, 以多个育人主体相互聚集, 多个育人场 域非线性融合为基础, 在培养大学生成长成才的道路 中形成一个良性发展的红色文化育人生态圈。构建出 这个生态圈需要三个基本条件, 一是红色基因能够在 各主体、各场域之间自由地流动。要达到大学生德智 体美劳全面发展, 由外在的推动作用转为自主地去摸 索, 就需要让红色基因在大学生主体之间相互地涌流, 在红色基因中汲取养分, 从中国共产党百年来的实践 真理中获得取得科学、知识的经验方法。并且能够在
思想政治教育生态圈中不停歇地进行再循环, 在一个 整体中发挥着乘数效应, 取得更好的影响效果。二是 理念同向引领下的育己生态圈。用共同的理念来引领 各育人主体，育人主体趋于同一目标，使之发生聚集 效应, 形成一个聚集体, 是高校思想政治教育生态圈 得以生成与发展的基础因素。这种共同的理念从根本 上说就是用红色基因来维系，坚定对红色基因的认同， 提供一个强大的内生动力。这种动力能够超越原本狭 险的单一主体意识, 获得一个系统化的生态联合。三 是场域共建引领下的育人生态圈。高校的育人行为主 要在不同场域进行, 不同场域之间有不同的育人效果。 在这些不同场域之间融入相应的红色基因元素, 其最 终的融合会产生非线性的结果, 其育人效应将会被放 大放宽，使红色基因在高校政治教育的生态圈中不断 强化, 发挥流的乘数效应。

\section{2. 基于 $\mathrm{CAS}$ 理论下高校红色基因育人生态圈 的建构逻辑}

多主体、多要素是教育生态系统的最基本特征。 因此, 要将红色基因更好地融入高校思政教育就需要 从单一维度向多维度融合发展转变, 构建主体融合、 场域延展、功能重构的三个同核心圈层的生态圈。从 CAS 理论多种理论指导下和价值涌现的角度出发, 分 析各维度的理论价值及逻辑关系, 从中梳理高校红色 文化育人生态圈建构逻辑与时代走向。

\section{1. 发生逻辑：以建构育已红色基因生态圈 为基础，凝聚主体共识}

CAS 在适应环境过程中会逐步建立起来的一种 极为复杂的机制。正如生态系统中的主体或环境在受 到刺激和调节时, 能够合理地调整其内部结构, 以指 导开展行动、预知未来的平衡规律。高校中育人主体 也是如此, 为了适应生存环境, 与环境和其他学科的 互动必须遵循一定的规律交互, 不断地交流信息、学 习或积累经验, 以改变其结构和规律功能, 使主体形 成与这个聚集体要求一致的思想意识, 并自觉遵守当 中的价值观念。在高校内部由于育人主体间的育人理 念, 工作的重点, 以及对待事情的处理方式均存在着 差异, 不同的差异难免导致出现矛盾和冲突, 常常体 现为人心不齐, 合作效率低下, 从而影响和削弱育人 效果。为了让红色基因更好地融入大学生思想政治教 育, 因通过各类育人主体聚集, 优势互补, 打破各主 体思想交流的壁垒，从而打造红色文化育人生态圈基 础。

把红色基因融入高校思想政治教育, 育己生态圈 作为第一圈层, 挖掘和发现各主体间共同意识, 促进 各主体间思想价值同向，实现主体观念协调是建构高 校 “红色基因育人生态圈” 的重要基础。将 CAS 作为 理论支撑从根本上把握红色基因融入大学生日常思 政教育的内在机理, 在适应性主体的交互作用下, 结 合聚集性, 通过充分挖掘各主体的基本特性及内在联 
系, 进一步打破系统内部各要素之间的壁垒, 在整体 的育人系统通过资源整合、优势互补, 各类育人主体 聚集，形成更高层次的育人系统，从而达到 “育己” 价值。红色基因体现的中国共产党人 “对党忠诚” “为 人民服务”“报效国家”“廉洁自律”“忠于职守” 等优秀品质 ${ }^{[7]}$, 是高校思想政治教育的宝贵资源。所 以高校在教育过程中要注重红色基因的丰富内涵对 于思想政治教育具有宝贵的引导作用。从而营造优良 的红色文化教育环境, 挖掘红色资源对高校 “三全育 人”具有现实指导、方向引领等重要意义。

\section{2. 发展逻辑：以建构育人红色基因生态圈 为巩固, 延展育人空间}

在育人生态圈中, 各主体间的交往是能达到相互 作用的动态联系，个体间的思想交流融合会在同一圈 层中得以实现, 主体间的良性互动实践中, 可以获得 精神世界的充盈。因此, 建构一个适合各主体间互动 的新圈层, 有利于各主体在成长过程中生发对内外环 境的归属感。同时, 各主体会在这种环境熏陶中自觉 汲取红色基因的营养。随着时代发展, 大学生生活场 域越来越呈现出立体化特征, 既包括大学生校园以社 团、班级、宿舍、食堂为场域的集体生活空间, 也包 括网络平台的社区群体交流虚拟空间。要围绕红色基 因 “流” 的涌动, 将红色基因融于大学生线上、线下 多场域, 结合 CAS 非线性发挥学生生活场域各种思政 资源的联动效应, 让红色基因在主体间、场域间流动, 进一步拓宽育人场地, 把各种育人力量资源汇聚推送 到学生需求的最近点, 使高校与家庭、社会相接壤, 建立在多个场域下满足学生的成长, 培育学生施展个 人才能、发挥个人价值、提高生存意义。

在现实的发展形成过程中, 为了实现主体之间的 特殊性, 主体聚集形成的聚集体的认同, 不同主体之 间的统一, 高校的生态圈教育必须要构建起多场域、 多层次、多样化的红色基因氛围, 使之打破传统的线 性规律, 实现价值关联、良性发展。在 CAS 理论融入 高校大学生生活空间中, 应由教师育人队伍引领部分 学生群体构建起班级、社团、党团等不同的“小场域”, 这些场域影响着大学生发展的外部环境。每个场域因 组织性质、人员构成、围绕主题不同, 红色基因在各 个场域的特征也就不同, 即为每个大学生提供了新的 成长可能, 又为个体提供了发展的限制。通过育人场 域融合，能够让红色基因在各个场域之间 “流动”， 在每个场域之间产生再循环效应, 大学生周而复始地 接受红色基因所带来的影响。同时, 在 “流” 的涌动 下, 通过非线性的相互反应, 相互适应, 各 “小场域” 之间可以形成新的协同和联动效应，聚集形成一个 “大场域”。“大场域” 具备各个 “小场域” 的特性, 同时又涌现出 “小场域” 所不具备的红色基因特性。 大学生在这个 “大场域” 中, 不仅可以充分占有、利 用和吸收各个 “小场域” 内红色基因的不同特点, 还 可以在整个 “大场域” 中获得新的生长与积累, 从而 实现自己的新发展。高校可以改变过去由院系分散到
单位建立教育实习基地的局面, 建立具有鲜明特色的 教育场域, 进一步拓宽育人场地, 使育人场域多样化, 让大学生在潜移默化中感受红色基因, 接受红色基因 的陶冶, 与知识学习相随, 与价值培育相行, 实现两 者的有机统一。把高校的培养目标, 校训, 校规等润 物细无声地内化为学子的道德情操, 发挥成风化俗的 作用, 实现 “育人” 价值, 加强大学生思想政治教育 中红色基因的整合。

\section{3. 涌现逻辑：以建构互育红色基因生态圈 为动力, 激活互育系统}

在互育生态圈中主要是全员参与、全过程衔接、 全方位覆盖，把握主体的育人统一性，促进成员良性 交互, 满足师生共同的利益需求、德育信仰和价值认 同, 与大学生的成长相伴相随, 形影不离。在这个过 程中每一个主体都有自身独特特性但也有共同点, 在 红色基因融入高校思政教育过程中要注重结合主体 的独特性与普遍性。这就要求在互育阶段, 在建设好 育已生态圈和育人生态圈的基础上将红色基因进行 多方面的整合，在教学中通过师生主体之间的双向互 动体现红色文化资源的育已、育人作用, 从而最大程 度地发挥红色基因在育己、育人的正面意义与现实意 义。

高校红色基因育人生态圈以互育价值为建构动 力点, 借由各主体与内外环境进一步融合的育人实践 开启高校红色基因育人价值实现，建构第三育人圈层。 一方面, 为了帮助学生提高理性思维, 培养道德修养, 从而实现红色基因主观世界的建构。另一方面，为了 促进多学科、多场域的互动, 与德育相结合, 营造红 色基因育人氛围, 生成稳定的、崭新的连接纽带, 实 现主体与环境良性互动, 涌现新的育人系统。新时期, 高校的育人场域更加宽广, 不局限限于校内的课堂之 中, 已经走出了校园的封闭空间, 走进了一个广泛开 放的生活世界。当前发展背景下, 育人各主体的数量 扩大, 育人内外环境的延展, 红色文化融入高校思想 政治教育这一复杂场域, 面临着更大的发展困难和现 实困难。需要着重把握红色基因融入高校思政教育的 复杂性，在主体上实现多元主体共同发力、多方人员 合力育人, 在空间上实现各场域全面覆盖, 各种复杂 元素的糅合, 能有效推动红色基因融入高校日常思政 教育的涌现，让思政教育朝特定的方向发展。把握学 生成长规律以及高校思政教学规律, 提高育人主体水 平、延伸育人空间，从而达到 “互育” 效果，实现红 色基因 “滴灌” 式传承，将红色基因的思政元素有机 地融入教学、管理、服务、实践、文化等各个方面, 有效提升课程体系与教学模式的建设, 提高思政教育 的有效性。

\section{3. 基于 CAS 理论下高校红色基因育人生态圈 的建构路径}

从红色文化育人生态圈的角度出发, 着眼于高校 
红色基因融入大学生思想政治教育的现实途径, 基于 CAS 理论指导下，以建构红色文化育人生态圈的理想 形态为突破口和重要参照, 从理念同向、场域共建以 及系统同构三大层面入手, 探究将高校红色文化育人 生态圈从理论推向实践的具体途径。

\section{1. 理念同向: 育己主体聚集, 为高校红色基 因育人生态圈铸魂}

在 CAS 中, 当主体在适应环境过程中会逐步建立 起来的一种极为复杂的机制。正如生态系统中, 当系 统受到适应性反应的刺激时, 个体或环境可以合理地 调整其内部结构, 以指导系统开展行动、预知未来的 平衡规律。在高校内部由于不同的职责分工以及不同 岗位上具有思想、行为特征的多种主体。主体间的育 人理念, 工作的重点, 以及对待事情的处理方式均存 在着差异, 不同的差异难免导致出现矛盾和冲突, 常 常体现为人心不齐, 合作效率低下, 从而影响和削弱 育人效果。加强红色基因在思想政治教育中的整合, 从 CAS 理论和实践经验看, 需要将不同文化价值观 加以整合, 因为凝聚各主体间共同的目标使命和兴趣 志向是建构育已红色文化生态圈的前提要义, 而主体 间共同的价值观念是构成和维系各主体间凝聚力的 精神纽带, 正是个体间的相互联系让同一圈层的成员 产生对所处生态环境中的身份认同感, 形成了对高校 红色文化育人的整体关照, 育人主体的汇聚与联合, 能使得简单的个体能量相加突破转变为整体凝集的 育人力量。高校育人功能丰富、组织架构复杂、教职 人员角色多变、学生成长需求多元, 要将红色基因真 正融入高校思政教育, 并且实现大学生自我驱动学习 成效, 亟需促进育己主体聚集, 促进教育理念同向而 行。使各主体间能够真正了解学习红色文化价值, 投 入到教育实践中，提高培训教学质量。

\section{2. 场域同建: 内外环境适应, 为高校红色基 因育人生态圈加固}

在 CAS 理论视角下, 红色基因具有环境场域育人 价值, 促进场域环境融合育人。马克思恩格斯选集中 指出: “创造环境, 同样环境也创造人”。 ${ }^{[8]}$ 目前, 学 生成长处于多维度立体空间之中, 需要充分考虑育人 场域的复杂性, 多方面拓展育人空间。育人多场域的 建构, 需要内外环境相互适应。外环境是校园文化环 境的外在表现载体, 这些载体包括校园的一草一花一 木, 一室一厅一栏, 以及校徽校旗等。这些都是看得 见、摸得着, 实实在在的外在环境。将这些红色元素 融入到校园物质文化中, 发挥大学生的价值熏陶作用。 精神文化环境是校园内环境, 是校园文化环境的内在 核心与校园灵魂。是校园精神面貌的重要体现。这就 要要求我们线下需围绕学生现实生活场景, 因地制宜 打造全方位、立体式、浸润式的育人时空。线上需发 挥网络社区作用, 利用各大网络平台对大学生的价值 引领, 实现线上线下同频共振、课堂内外综合融通的
全域性育人景象。具体需要: 第一, 利用团日活动、 雷锋活动等红色形式将红色文化的影响力与推广力 深深体现在高校学生生活中; 第二, 利用 “互联网+” 的思想, 利用抖音、微信公众号发布具有吸引力、关 注力同时具有正能量的作品, 与校内思政工作相配合 进行微环境融入。第三, 需要在教学中结合 CAS 理论 中的 “适应性群体” 方法论与学生进行有效互动, 对 不同情况的学生采取多种方式的培养, 利用矛盾的特 殊性与普遍性在学习中因材施教。内外环境的相互嵌 套使红色文化资源育人发挥促进学生思想政治觉悟 提高作用。

\section{3. 系统同构: 价值系统涌现, 为高校红色基 因育人生态圈注力}

育人内部模型的演化实质上是一个具有强大内 部动力的互育生态圈。红色文化融入大学生高校思想 政治教育基于 CAS 理论指导下作为一种流的贯通能为 各主体与各场域能提供了紧密联结的精神纽带, 并获 得具有超越界限的有机融合, 具有推动高校育人体系 由单一的单向机械运转向有机统一的生态圈运转模 式转变, 实现育人体系的质变升华。优化红色基因融 入高校思想政治教育的机制、方式，为高校育人生态 系统注入最基本最深层的力量, 并使之成为社会大育 人系统的重要一环。高校育人生态系统并不是单一的 系统, 而是有明确的育人目标和正确的价值理念的嵌 入, 是由若干个元素构成, 遵循特定的规律运转, 与 社会育人体系有着不可分割的关系，与社会育人体系 形成有机关联。在这个过程中充分发挥适应性主体群 体性交往的集体教育力量，打造集红色基因传承、日 常思政、师生互动、争先创优、党团共建、生活服务 多功能一体的红色基因传承生态圈。生态圈的嵌入使 红色基因融入大学生日常思政教育成为长效机制, 在 这个生态圈中任何个体都能够根据自身情况与周围 人和环境产生联系。红色文化作为这个生态圈的 “能 量” 在这个生态圈里面不断地流动, 形成多元主体共 聚, 多重场域共存, 多种方式共用的立体化育人有机 体, 帮助高校个体内化和认同红色基因。这种育人模 式不仅是为了帮助大学生完成个体发展的探索, 自我 主观世界的内部系统的建构, 在红色基因中汲取养分, 提升自身的道德修养, 更是依据大学生在不同阶段的 成长需要以及教学资源分布的不充分之间的矛盾, 提 供给每个大学生多姿多彩的教育实践活动, 开发出个 体的个性特征, 包罗大学生的普遍性, 促进大学生的 全面发展。通过红色基因实践活动和行动, 促进主体 之间的相互连接, 相互作用, 使主体沉浸在红色基因 中, 从被动地接受红色基因, 自在的发展转变为主动 地吸收红色基因, 自知自觉地采取实际行动去改变, 以一种科学有效的方式, 快速地提升自我, 实现质的 飞跃性发展。这是一个具有聚集性、协同性、复杂性、 适应性、并能发挥预期功能的育人制度体系，它遵循 思想政治教育规律、教书育人规律、大学生成长成才 规律，围绕 “立德树人” 根本任务，与时俱进高校思 
想政治工作的内容供给、话语体系与教育方式，及时 反馈评价、总结经验、修正完善，使高校红色基因育 人工作不断因事而化、因时而进、因势而新。

\section{4. 结语}

习近平在全国高校思想政治工作会议上强调要 将思想政治工作贯穿于教育教学全过程, 因此构建 CAS 理论视角下红色基因融入高校思想政治教育成为 了新时期的必然要求。在教学中结合 CAS 理论中的“适 应性群体” 方法与学生进行有效互动, 对不同情况的 学生采取多种方式的培养, 利用矛盾的特殊性与普遍 性在学习中因材施教, 使红色文化资源育人作用得到 充分发挥, 促进学生思想政治觉悟提高。而构建育人、 育已、互育生态圈则是梳理高校红色文化育人建构逻 辑与时代走向的核心, 也是实现红色基因育人的关键 点和难点。把握红色基因融入高校思政教育的复杂性, 在主体上实现多元主体共同发力、多方人员合力育人, 在空间上实现各场域全面覆盖, 各种复杂元素糅合, 能有效推动红色基因融入高校日常思政教育的涌现， 让思政教育朝特定的方向发展。基于本文 CAS 理论分 析, 高校可以改变过去由院系分散到单位建立教育实 习基地的局面, 让具有鲜明特色的教育场域, 进一步 拓宽育人场地, 使育人场域多样化让大学生在潜移默 化中感受红色基因, 接受红色基因的陶冶, 与知识学 习相随, 与价值培育相行, 实现两者的有机统一。把 高校的培养目标, 校训, 校规等润物细无声地内化为 学子的道德情操, 发挥成风化俗的作用, 实现“育人” 价值, 加强大学生思想政治教育中红色基因的整合。 高校在教学实践基础上, 从理念同向、场域共建以及 系统同构三大层面入手, 将更加有效地探究高校红色 文化育人生态圈从理论推向实践的具体途径, 构建行 之有效的高校红色基因育人生态圈。

\section{REFERENCES}

[1] Xi Jinping stressed the importance of learning the party's history and thinking and doing practical work in the party history education and mobilization conference. He welcomed the founding party with outstanding achievements. $\mathrm{Li}$ Keqiang, Li Yang, Zhao Leji, Han Zheng and Wang Qishan attended the 100th anniversary party members of contemporary [J]., 2021, $\{4\}$ (05): 15-17.

[2] [3] Collected works of Marx and Engels [M]. Volume I. Beijing. People's publishing house, 2009.524.520

[4] [US] Lawrence Arthur kraming, translated by Zhou Yujun, history of American Education: the process of colonial period, 1607-1783 [M]. Beijing. Beijing Normal University Press, April 2003
[5] Liu Yanyun. Research on Ashby's ecological thought of Higher Education [D]. Huazhong University of science and technology, 2004

[6] [US] John Holland. Hidden order: adaptability creates complexity $[\mathrm{M}]$. Translated by Zhou Xiaomu, Han Hui, Shanghai Science and Technology Education Press, October 2011

[7] Xu Guifang. Value implication and Realization of inheriting red gene in Ideological and political theory course in Colleges and universities in the new era $[\mathrm{J}]$. Educational theory and practice, 2020,40 (33): 33-35.

[8] selected works of Marx and Engels [M]. Volume I. Beijing. People's publishing house, 1995.92 